\title{
Early Career Investigator: Erlinda R. Ulloa
}

\author{
Erlinda R. Ulloa ${ }^{1,2 凶}$ \\ (c) The Author(s), under exclusive licence to the International Pediatric Research Foundation, Inc 2021
}

Pediatric Research (2021) 90:924-925; https://doi.org/10.1038/s41390-021-01733-x

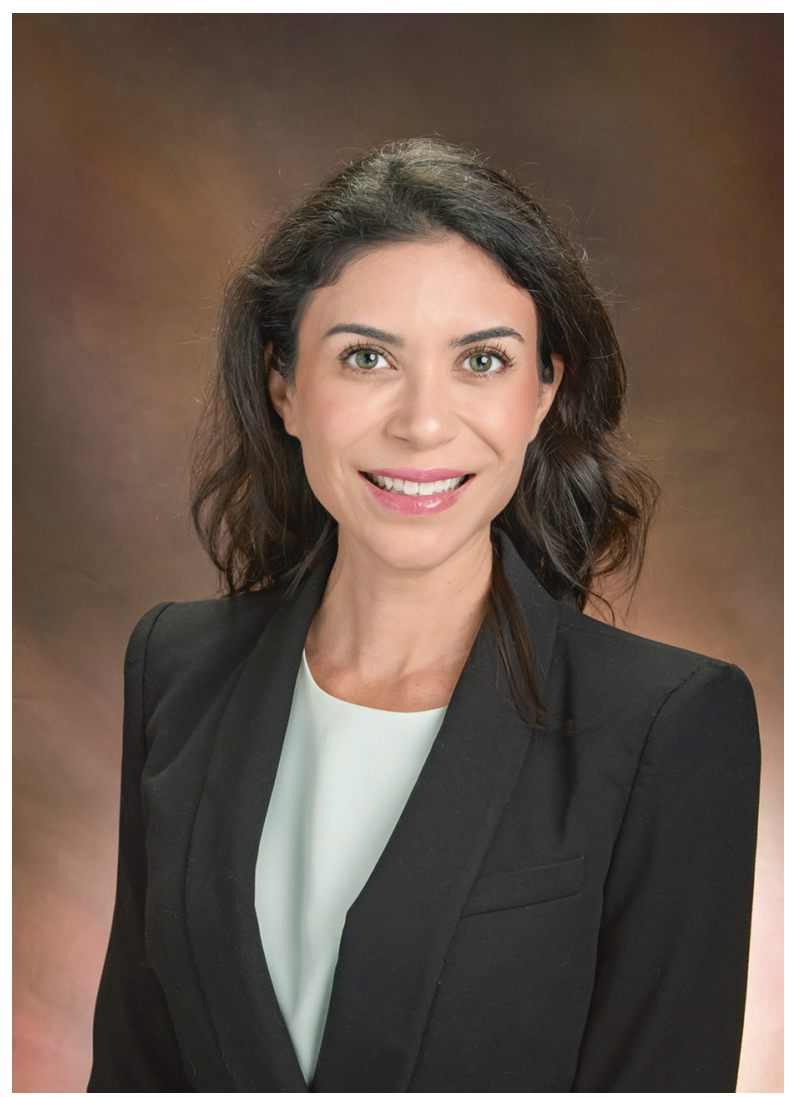

As a Southern California native, I graduated from University of California (UC) San Diego with Bachelor of Science degrees in Physiology \& Neuroscience and Psychology. My love of travel and global health led me to Argentina on Fulbright and Fogarty Fellowships, where I conducted research for 2 years. I subsequently completed medical training at Stanford University School of Medicine, where I also earned a Master of Science in Microbiology and Immunology, and worked with the CDC as a Hubert Global Health Fellow in Kenya. I went on to complete a residency at Boston Children's Hospital/Boston Medical Center. With support from the Pediatric Scientist Development Program, I completed my clinical infectious diseases training at the Children's Hospital of Philadelphia concurrent with postdoctoral research training in the laboratory of Professor Victor Nizet at UC San Diego. I am now an Assistant Professor in the Department of Pediatrics, and a faculty member for the Program in Medical Education for the Latino Community at the UC Irvine School of Medicine. I am also an Attending Physician in the Division of Infectious Diseases at the Children's Hospital of Orange County.

Raised by my feisty, Puerto Rican grandmother (who is now 101 years old!) - it is the love of this strong and passionate woman that has inspired me throughout my career. I was drawn to Pediatrics because it combines my passion for patient care, research, community service, and advocacy; all of which continues to fuel my medical and scientific endeavors. Although I have conducted research since college, it was my patient care experiences, particularly those during my clinical training, that strongly influenced my research path. One too many times, I had to explain to a devastated parent that their critically ill child had an infection resistant to multiple antibiotics or stand at the bedside of a child receiving dose-reduced chemotherapy because of disseminated, drug-resistant infection. While antimicrobial therapy is undoubtedly one of the greatest success stories in medicine, in moments such as these, I recognize the urgent need to improve antimicrobial treatment strategies. Towards that end, my laboratory examines novel treatment strategies for difficult to treat or drug-resistant pathogens. Recently, in light of the COVID19 pandemic, my research focus has expanded to shed light on the transmission, immunological responses, and post-acute sequelae of SARS-CoV-2 in children. My laboratory is supported by the NIH/NIAID, a Harold Amos Award/Robert Wood Johnson Foundation, and a UC President's Award.

I would like to conclude by emphasizing that my accomplishments would not have been possible without the support and guidance of several key mentors and role models. I am indebted to all those who have helped me along my path. My advice to trainees is to follow your passion, think big, and seek out good mentorship. The influence of even one good mentor on your trajectory cannot be overstated.

\section{FUNDING INFORMATION}

This work was supported by the Orange County Health Care Agency, Robert Wood Johnson Foundation, and the National Institute of Allergy and Infectious Diseases, NIH (K08 Al151253-01).

\section{COMPETING INTERESTS}

The author declares no competing interests.

${ }^{1}$ Department of Pediatrics, University of California Irvine School of Medicine, Irvine, CA, USA. ${ }^{2}$ Children's Hospital of Orange County, Orange, CA, USA. ${ }^{\varpi}$ email: chulie.ulloa@uci.edu 
ADDITIONAL INFORMATION

Correspondence and requests for materials should be addressed to Erlinda R. Ulloa.

Reprints and permission information is available at http://www.nature.com/ reprints
Publisher's note Springer Nature remains neutral with regard to jurisdictional claims in published maps and institutional affiliations. 